\title{
Lunar Contour Crafting - A Novel Technique for ISRU- Based Habitat Development
}

\author{
Behrokh Khoshnevis* \\ University of Southern California Information Sciences Institute, Marina del Rey, CA, 90292 \\ Melanie P. Bodiford ${ }^{\dagger}$, Kevin H. Burks ${ }^{\varrho}$, Ed Ethridge ${ }^{*}$, and Dennis Tucker ${ }^{\infty}$ \\ NASA/Marshall Space Flight Center, Huntsville, AL, 35812 \\ Won $\mathrm{Kim}^{*}$ \\ NASA/Jet Propulsion Laboratory, Pasadena, CA, 91100 \\ Houssam Toutanji \\ University of Alabama in Huntsville, Huntsville, AL, 35899 \\ and \\ Michael R. Fiske \\ Morgan Research Corporation, Huntsville, AL, 35805
}

\begin{abstract}
As the nation prepares to return to the Moon, it is apparent that the viability of long duration visits with appropriate radiation shielding/crew protection, hinges on the development of Lunar structures, preferably in advance of a manned landing, and preferably utilizing in-situ resources. Contour Crafting is a USC-patented technique for automated development of terrestrial concrete-based structures. The process is relatively fast, completely automated, and supports the incorporation of various infrastructure elements such as plumbing and electrical wiring. This paper will present a conceptual design of a Lunar Contour Crafting system, designed to autonomously fabricate integrated structures on the Lunar surface using high-strength concrete based on Lunar regolith, including glass reinforcement rods or fibers fabricated from melted regolith. Design concepts will be presented, as well as results of initial tests aimed at concrete and glass production using Lunar regolith simulant. Key issues and concerns will be presented, along with design concepts for an LCC testbed to be developed at MSFC's Prototype Development Laboratory (PDL).
\end{abstract}

\section{Introduction}

As the nation prepares to return to the Moon and subsequently to Mars, it is apparent that the viability of long duration visits with appropriate radiation shielding/crew protection, hinges on the development of habitat structures, preferably in advance of a manned landing, and preferably utilizing in-situ resources. A relatively large number of habitat structure configurations can be developed from a relatively small set of in-situ resource-based construction products, including, blocks, raw regolith (loose, bagged, or use of caves/lava tubes), reinforced concrete, and glass products. A much larger group of habitat designs can be developed when "imported" materials are brought from

\footnotetext{
*Professor, Department of Industrial \& Systems Engineering

+ Project Manager, Habitat Structures Technology Development/SY10

${ }^{a}$ Lead Test Engineer, Systems Integration and Test Branch/EI52

* Materials Scientist, Exploration Science and Technology Division, Exploration Research Branch/XD42

${ }^{\infty}$ Materials Physicist, Advanced Optical Concepts Division/XD31

Senior Member of Technical Staff, Telerobotics Research and Applications Group

${ }^{\text {E }}$ Professor, Department of Civil \& Environmental Engineering

${ }^{\S}$ Space Architecture Team Lead, Habitat Structures Technology Development/SY10, AIAA Senior Member
} 
Earth, including thin films and liners, and foldable, or expandable metal structures. These, and other technologies have been identified, and are currently being subjected to a rigorous trade study evaluation with respect to exploration and other performance criteria by the Habitat Structures group within NASA/Marshall Space Flight Center's In Situ Fabrication \& Repair (ISFR) team. One such technology, Contour Crafting (CC), is the focus of this paper.

\section{Contour Crafting Process Development}

Conventional methods of manufacturing automation do not lend themselves to construction of large structures with internal features, especially if various other components (such reinforcement, pipes, sensors, etc.) are to be installed within the structure. This explains why the evolution of construction automation has been slow. A promising new automation approach is layered fabrication, generally known as solid free form fabrication or rapid prototyping. However, most of the current layered fabrication methods are limited by their ability to deliver a wide variety of materials applicable to construction. Additionally, they are severely constrained by the low rates of material deposition which makes them attractive only to the fabrication of small industrial parts.

Invented at USC, Contour Crafting is an additive fabrication technology that uses computer control to exploit the superior surface-forming capability of troweling in order to create smooth and accurate planar and free-form surfaces out of extruded materials. Some of the important advantages of CC over other layered fabrication processes are possibility of fabrication with large layer height without compromising surface quality, unprecedented surface quality, higher fabrication speed, and a wider choice of materials. The key feature of CC is the use of trowels in conjunction with a robotic system. Artists and craftsmen have effectively used simple tools such as trowels, blades, sculpturing knives, and putty knives for forming materials in paste form since ancient times. However, despite the progress in process mechanization with computer numerical control and robotics, the primary method of using these simple but powerful tools is still manual, with the consequent result that their use is limited to model building and plaster work in construction. In CC, computer control is used to take advantage of the superior surface forming capability of troweling to create smooth and accurate, planar and free-form surfaces. CC is a hybrid method that combines an extrusion process for forming the object surfaces and a filling process (pouring or injection) to build the object core. As may be seen in the CC nozzles in Figure 1, the CC nozzle has a side trowel. As the material is extruded, the traversal of the trowels creates smooth outer and top surfaces on the layer. The side trowel can be deflected to create non-orthogonal surfaces. The extrusion process builds only the outside edges (rims) of each layer of the object. After complete extrusion of each closed section of a given layer, if needed, filler material such as concrete can be poured to fill the area defined by the extruded rims.
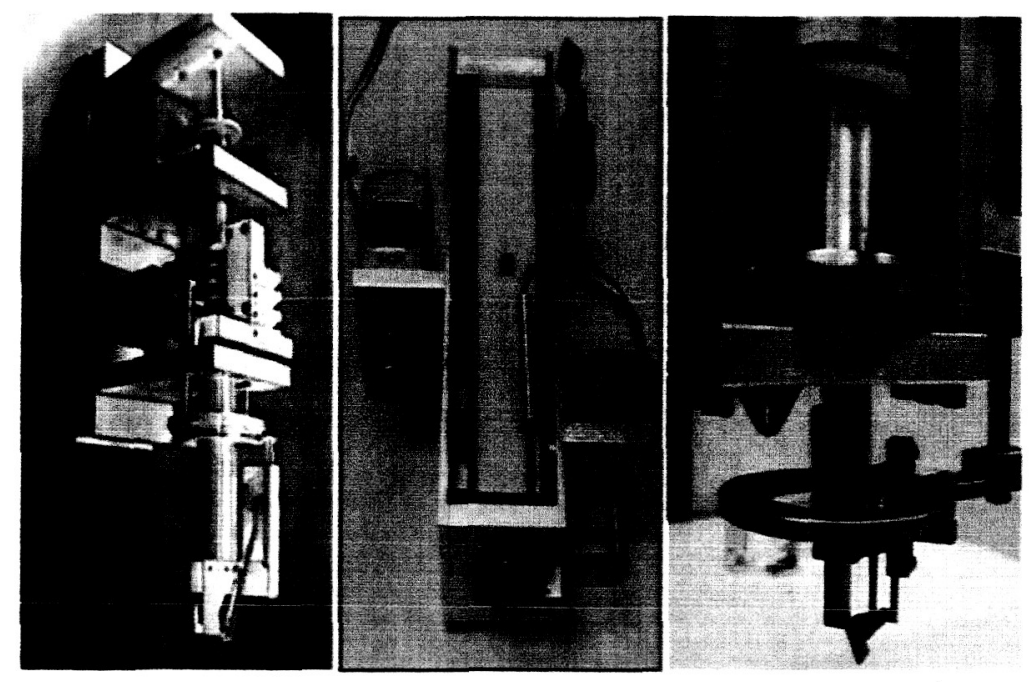

Figure 1. CC nozzle assemblies for plastics and ceramics

The potential for $\mathrm{CC}$ in building construction became evident after successful experimentation with various construction materials such as clay, plaster and concrete. One possible application of CC in building construction is

2

American Institute of Aeronautics and Astronautics 
depicted in Figure 2 where a gantry system carrying the nozzle moves on two parallel lanes installed at the construction site. A single house or a colony of houses, allowing for a different design for each structure, could be automatically constructed in a single run. Conventional structures can be built by integrating the CC machine with a support beam picking and positioning arm, and adobe structures may be built without external support elements using shape features such as domes and vaults. Conventional roofs may be built using standard beams with a thin panel attachment to hold the roof construction material delivered by the CC nozzle. Several animations of the building construction process by CC may be viewed at: www.contourcrafting.org.

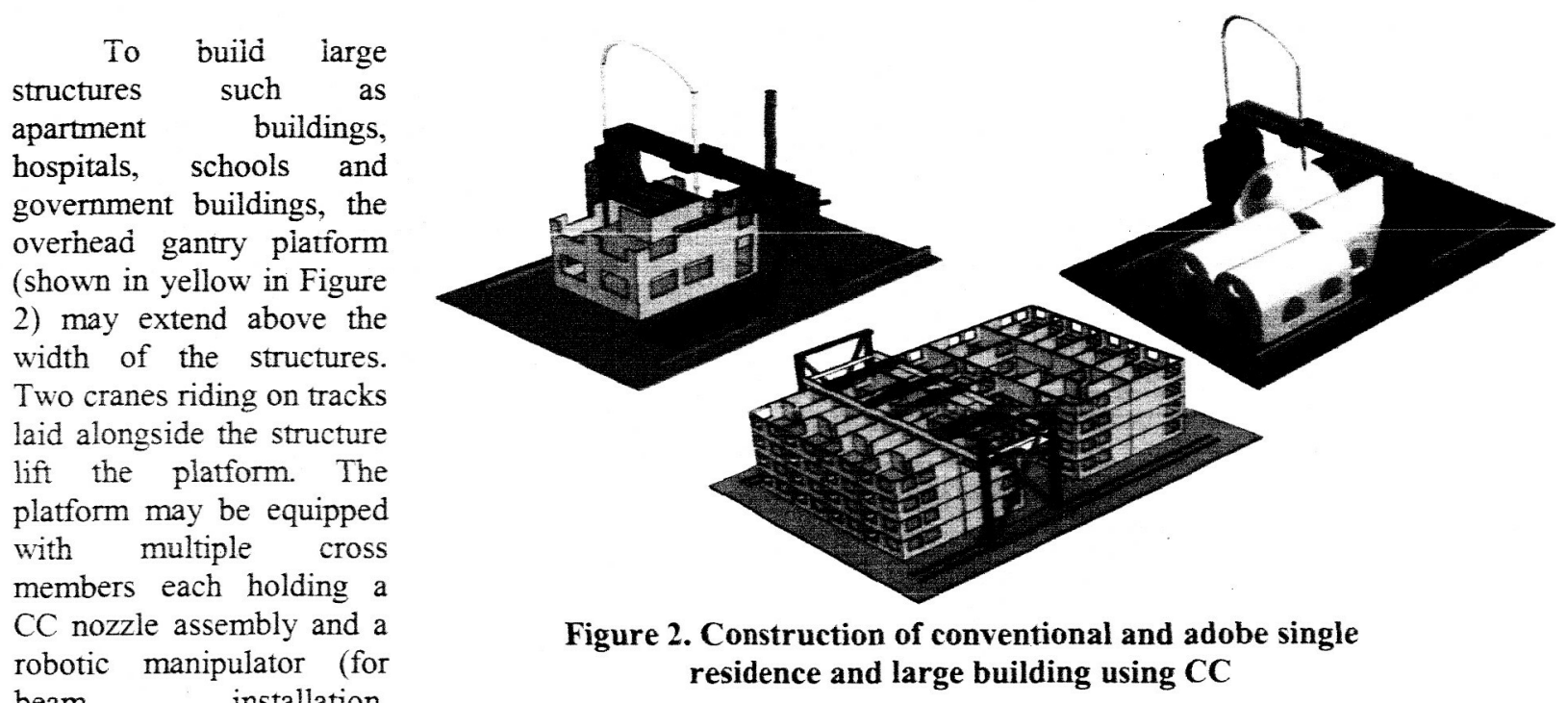

beam installation

plumbing, etc.). The integrated construction system using $\mathrm{CC}$ also includes automatic methods for reinforcement, plumbing, electrical and communication network wiring, and sensor embedding (see Figure 3).

Towards improving the strength of large structures built through $\mathrm{CC}$, we have investigated the use of a variety of reinforcements. For example, Figure 4 shows pictures from our experiments with coil reinforcement. Owing to the high extrusion pressures prevailing in CC compared to other layered free-form fabrication techniques, the extrudate thoroughly adheres itself around the coils without causing any internal discontinuities.
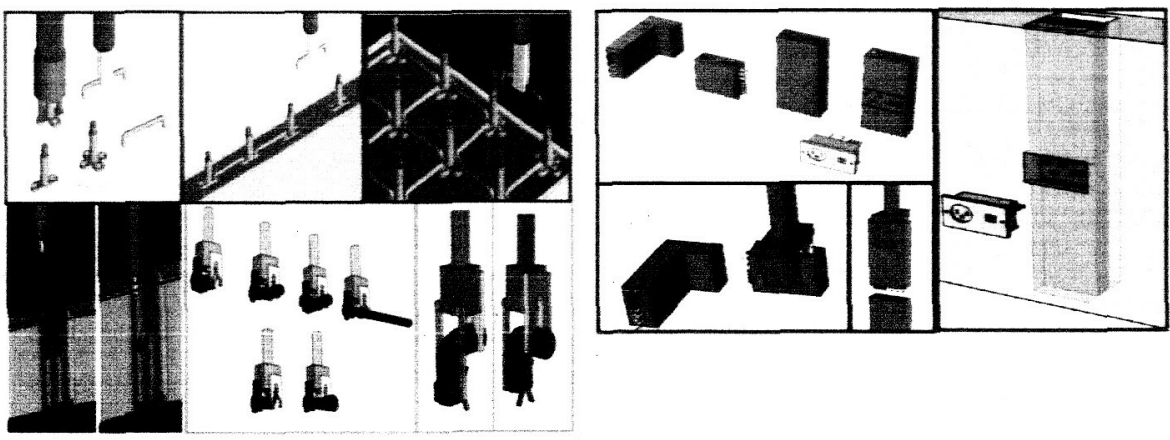

Figure 3. Automated reinforcement, plumbing and electrical networks

Figure 5 shows the current state of the CC technology. Under prior projects (two NSF and one ONR) we have conducted extensive experiments to optimize the CC process to produce a variety of small scale $2.5 \mathrm{D}$ and $3 \mathrm{D}$ parts with square, convex, and concave features, made with a variety of materials, including ceramics. Through the first year of our current NSF project we have constructed a machine that is capable of building full scale straight wall sections out of concrete (right side of Figure 5). These experiments establish the feasibility of CC in construction of various geometrical features and feasibility of full scale implementation. More details on the CC process are provided in References 1-5. 


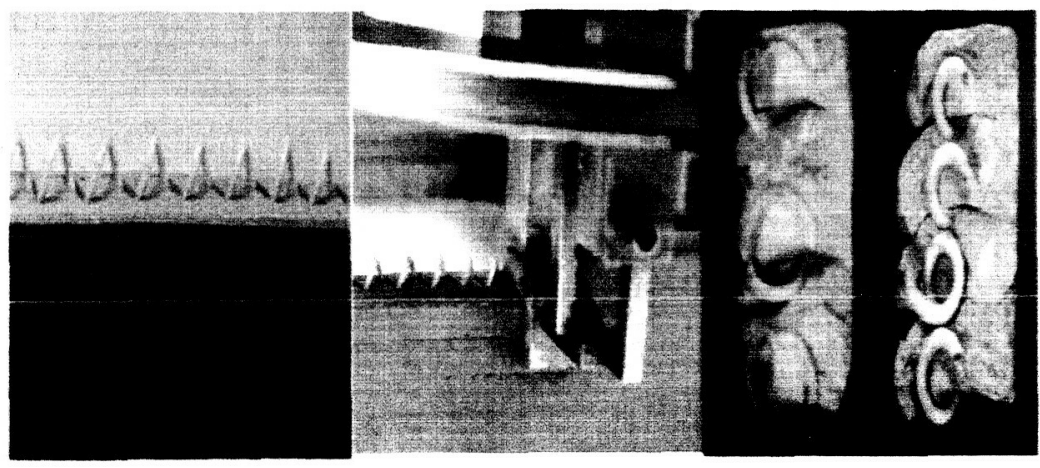

Figure 4. Reinforcement using steel coil
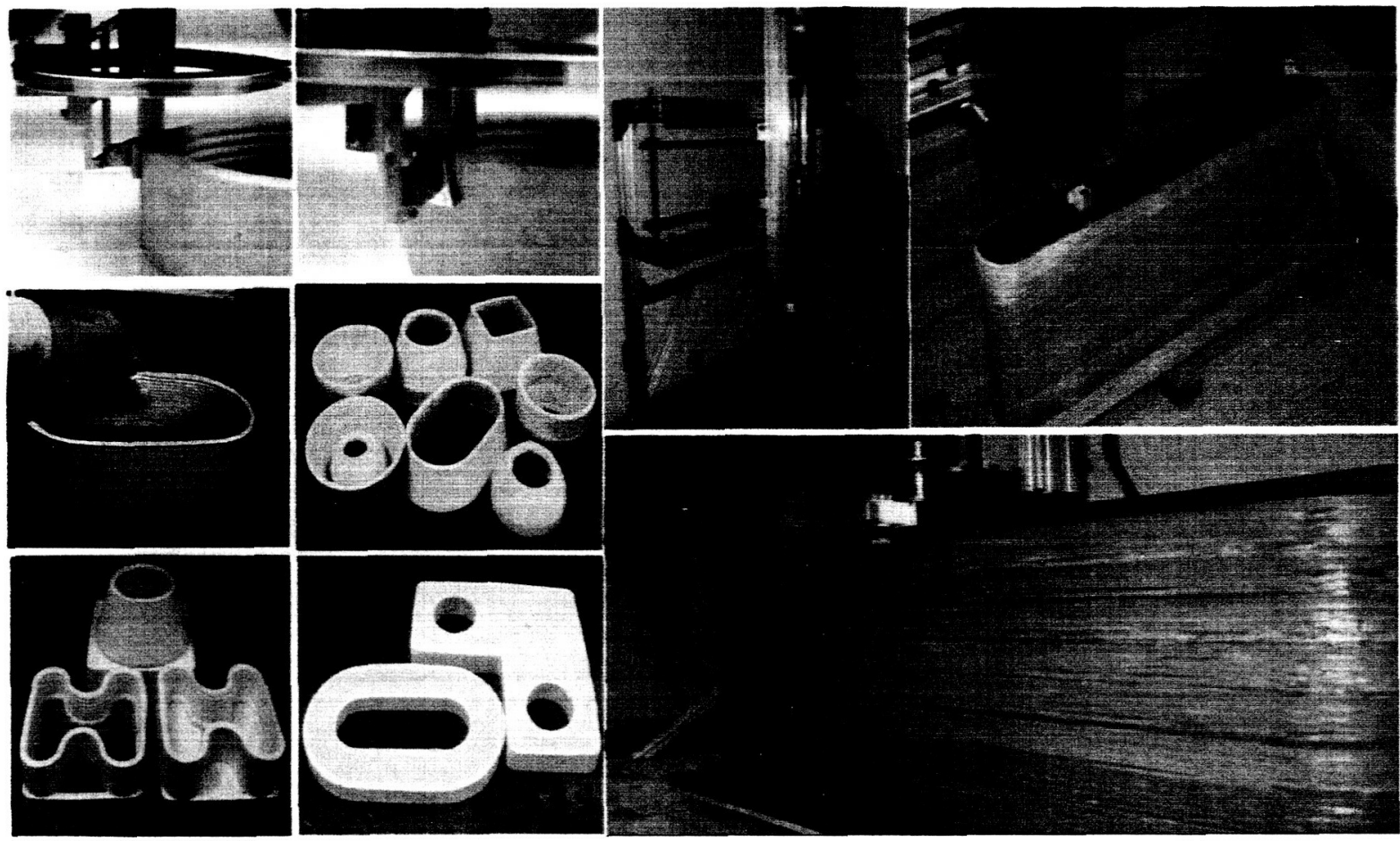

Figure 5. CC in operation, representative 2.5D and 3D ceramic shapes, and full-scale concrete walls

\section{Robotic Operations for Lunar Construction}

CC technology requires accurate, variable-speed motion control of the nozzle over the entire construction work volume. Since a large crane with a long boom makes it difficult to achieve good accuracy and speed, a gantry frame will likely be a better choice. Further, it is best to make the gantry frame mobile in order to eliminate on-site human assembly and disassembly. Finally, this mobile gantry robot should be collapsible or retractable for launch and deployment at the lunar construction site. A conceptual deployment sequence of the mobile gantry frame is shown in Fig 6. A typical operational scenario of such a mobile gantry robot is as follows:

1. Launch the mobile gantry robot with the gantry collapsed or retracted

2. After landing, traverse to the construction site with the gantry still retracted. 
3. Upon arrival to the construction site, deploy the gantry

4. Perform self alignment and leveling of the gantry

5. Ensure that the nozzle, hopper, and material delivery system operate properly.

6. Perform Contour Crafting construction

7. After the completion of the construction, retract the gantry into transport configuration.

8. Traverse to a new construction site for the next construction

The concept development and trade study of the mobile gantry robot design for CC lunar construction includes the study of mobile platform design, deployable gantry, interface with nozzle and material delivery, leveling using stabilizing legs, passive compliant joints and locking, sensor-based motion and mobility control, and supervisory autonomous control. A lunar mobile gantry robot can be viewed as two rover platforms connected by a crossbeam. Two mobile rovers must be able to move without damaging the rovers and crossbeam. Passive compliant joints and position sensors will be utilized for safe and reliable mobility control. The mobile platforms will most likely to have four wheels with steering and drive motors for each wheel. The mobile platforms will also be equipned with CPU's as well as various sensors such as inertial measurements units (IMU's), laser sources, and cameras.
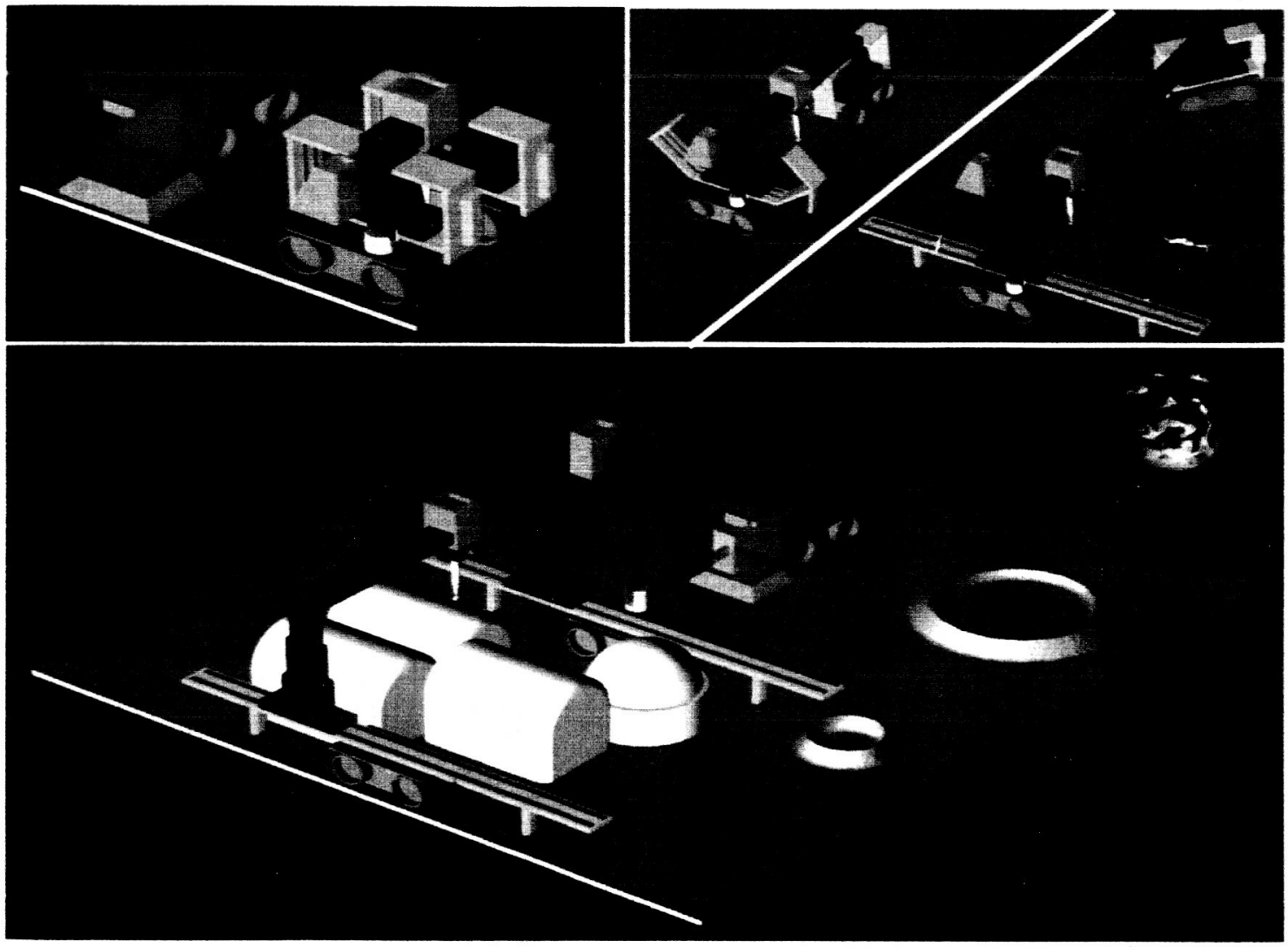

Figure 6. Mobile gantry $\mathrm{CC}$ deployment sequence: launched rovers (upper left), unfolding horizontal rails and extending cross beam (upper right), $\mathrm{CC}$ in operation

The mobile gantry robot requires as many as seven retractable beams for lunar launch and deployment - four horizontal base beams, two vertical posts, and one top crossbeam. Fig. 7 illustrates different methods of deployable beams: 1) telescoping, 2) unfolding, and 3) one-time or multiple-time retractable truss structure. Stabilizing legs will be attached to the ends of four horizontal base beams, which will enable leveling of the gantry.

The mobile gantry robot will have passive compliant joints during the traverse, deployment and retraction operations to allow flexing of the structure to reduce stress on the components. These joints will have to be locked after the alignment, leveling and calibration operation. Kinematic and dynamic analysis of the gantry robot during 
these operations will be performed in the initial stages of the design to provide engineering specifications for the joints and the other structural components of the robot.

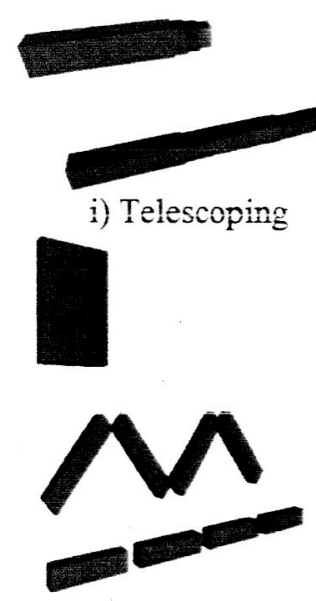

ii) Unfolding beam

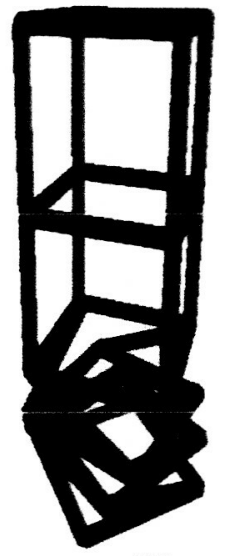

iii)

Deployable/retractable

Figure 7. Alternative beam designs

Even with Contour Crafting's superior automation capabilities, some portions of the gantry robot deployment may still need human interactions. Therefore, we will implement supervisory control as well as shared control for mobile gantry robots. In supervisory control, the human operator acts as a supervisor issuing high-level autonomous commands and monitoring the performance of remote command execution. In shared control, remote autonomous control and human manual control are shared simultaneously. The human operator can intervene when an anomaly occurs and takes corrective actions. The human operator can command the mobile gantry robot either from the lunar surface or from the earth. Commanding and monitoring from Earth requires, however, addressing the issue of the round-trip communication time delay of 2 to 4 seconds including satellite/ground relays. JPL's contribution builds on the prior work in the area of end-to-end space-based teleoperated robotic systems. Prior JPL research experiences include close cooperation and coordination of multiple robots, robot work crews, predictive display and shared compliant control with time delay, automated avoidance of robot collision with the structure, planning paths for robot motion, computer vision assisted virtual reality calibration, graphical aid, and graphical user interface (GUI). An integrated prototype of a lunar mobile gantry robot requires the design and building of mobile platforms, stabilizing legs, and gantry frame. This effort needs to be integrated with the Contour Crafting nozzle, hopper, and material delivery system. References 6-14 provide more details on some of the points presented here.

\section{Concrete Development}

\section{A. In Situ Lunar Materials}

Cementitious materials such as concrete consist of cement, water, and aggregates, and are produced by curing mixed material in molds. Cement can be produced by lunar Anorthite and glass by means of sintering and crushing processes, while water can be made by reducing lunar oxides with hydrogen (Ref. 15). Hence, hydrogen would be the only required material to be transported from Earth. Some lunar materials like lunar glass, basalt, and anorthite contain 9 to $19 \%$ by weight of $\mathrm{CaO}$ and are considered potential raw materials for cement production. By comparison, Portland cement generally consists of $\mathrm{CaO}$ content of around $64 \%$ by weight and is contained in a relatively small area of the $\mathrm{CaO}-\mathrm{Al}_{2} \mathrm{O}_{3}-\mathrm{SiO}_{2}$ phase diagram (Ref. 16). From a mineralogical standpoint, lunar materials are classified as pyroxene, olivine, plagioclase feldspar, ilmenite, and spinel. Among these, pyroxene and plagioclase feldspars are possible sources for calcium oxide (Ref. 16). Table 1 shows the mineral compounds of lunar cement compared to that of Portland cement. The most important compounds contributing to the strength of hydrated cement paste are $\mathrm{C}_{3} \mathrm{~S}$ and $\mathrm{C}_{2} \mathrm{~S}$ (Ref. 17). However, research shows that this is not a problem in developing the required compressive strength of lunar concrete. In fact, a tested lunar mortar mix has been shown to be capable 
of developing 3,176 psi compressive strength without gypsum being added to the mix and 5,627 psi with gypsum (Ref. 16).

Table 1. Mineral Compounds of Lunar Cement by Mass\% (Ref. 16)

\begin{tabular}{|l|l|l|l|l|}
\hline & $\mathrm{C}_{3} \mathrm{~S}$ & $\mathrm{C}_{2} \mathrm{~S}$ & $\mathrm{C}_{3} \mathrm{~A}$ & $\mathrm{C}_{4} \mathrm{AF}$ \\
\hline Lunar Cement & 30.1 & 29.7 & 31.2 & 4.6 \\
\hline Portland Cement & 55.0 & 20.0 & 12.0 & 9.0 \\
\hline
\end{tabular}

Even though concrete appears to be well suited for lunar structures, the production of concrete on the Moon poses many challenges. The mixing and placing of concrete in a microgravity environment is not well understood and has been the subject of recent research (Ref. 18). The mixing and placing of concrete on earth is largely dependant on gravity for uniform consolidation of cement particles and proper hydration. It is seen that traditional wet mix methods are not adequate for a lunar environment especially due to the water constraint. Three methods of producing concrete in a microgravity environment are discussed: the traditional wet-mix method, the DryMix/Steam Injection (DMSI) method, and the waterless sulfur/regolith mix (WSRM) method.

\section{B. Wet-Mix Method}

On September 30, 1994, the space shuttle Endeavour roared off the launch pad at Florida's Kennedy Space Center carrying the world's first Portland cement-based-concrete experiment into space (Ref. 18). Researchers from the University of Alabama in Huntsville and Master Builders Inc., carried out the study to help shape the future of concrete technology. The NASA space shuttle program offered a payload carrier called a Get Away Special (GAS) container where small experiments can fly into orbit in the cargo bay of a space shuttle. The objectives of this study were (i) to determine the feasibility of mixing concrete in microgravity environment, (ii) to design and develop an experimental mixing chamber for concrete in microgravity, (iii) to perform experiment abroad in orbit, and (iv) to evaluate concrete properties in microgravity environments.

Both the microgravity and control concrete samples underwent petrography examinations. Results showed that both samples have similar physical features. However, the control sample contains some air voids while the microgravity sample does not. Optical and scanning electron microscopy also revealed that the space concrete has more visible crystalline hydration products uniform in size and distribution throughout the matrix than does the control sample (Fig. 8). Some of the observed difference between the two concretes still are not fully understood (Ref. 18).
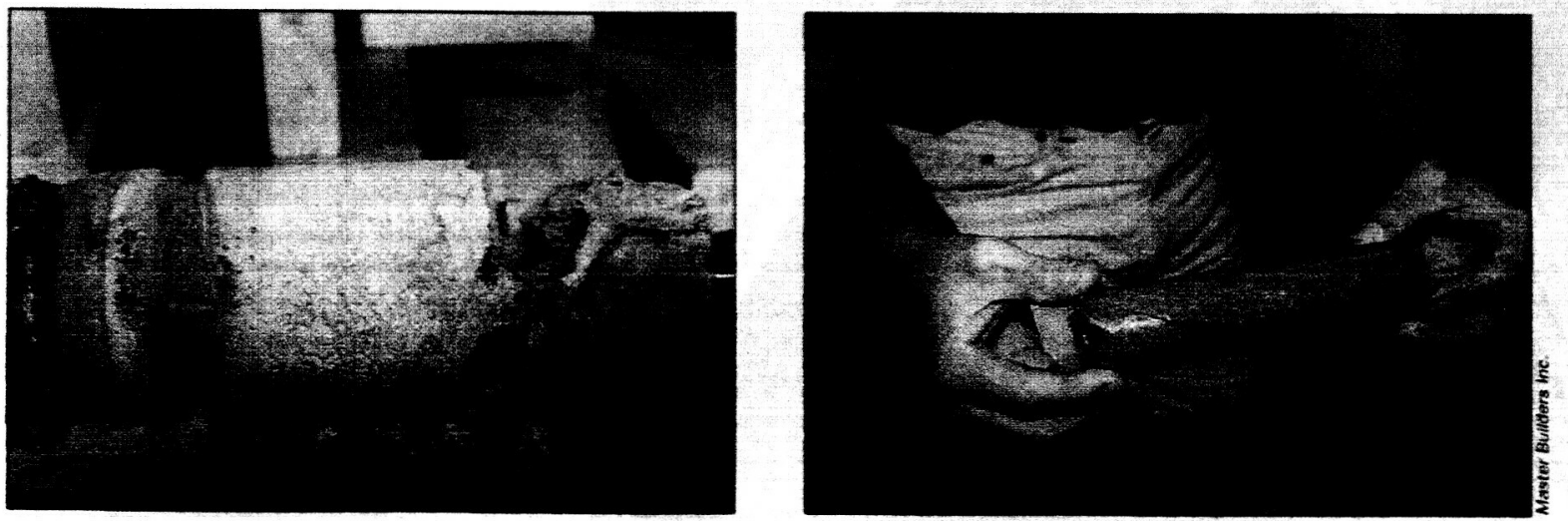

Figure 8. Concrete Samples Prepared in Microgravity Environments (Ref. 18)

\section{Dry-Mix/Steam-Injection (DMSI) Method}

A seemingly better alternative to the wet-mix methods is to mix cement and aggregate in a dry state and expose the mixture to steam in a confined chamber to enforce hydration at elevated temperatures and pressures. When steam is injected onto cement, the steam particles that are charged with both heat and kinetic energy bombard cement particles in a confined space. This bombardment results in a transient heat transfer to enhance hydration. In 
the DMSI process, cement particles near the exposed surface of the cube hydrate first. The hydrates develop micropores letting the steam diffuse to the core of the concrete allowing for complete hydration (Ref. 19). The DMSI method results in less cement consumption than that of the wet-mix procedure due to the increased surface exposure of cement particles. It also offers advantages of shorter hydration time, higher strength and better workability than the conventional wet-mix procedure (Ref. 20 ).

\section{Waterless Sulfur/Regolith Mix (WSRM) Method}

Even though the existence of ancient cemetery ice deposits in the South Pole Aitken basin has been confirmed by Clementine bistalic radar experiments, still water is undoubtedly the most precious commodity on the Moon and its use for cement based concrete construction is doubtful, plus the fact that major constituents of Portland cement are present as strongly bound stable rock forming minerals, which means complex chemical reactions are required to convert lunar rocks and minerals to cement. Experiments carried out on lunar soil samples returned by Apollo missions revealed that sulfur could be extracted from lunar soil by heating it at moderate temperature (of the order of $1000-1200{ }^{\circ} \mathrm{C}$ ), which can be achieved with standard solar concentrators on the Moon (Ref. 21). Sulfur is sufficiently abundant on the Moon that it may be available as a by-product from lunar oxygen production or gas recovery. Analysis of the lunar samples returned by the Apollo missions indicate that sulfur, $11^{\text {th }}$ in weight abundance, is available in the mare soils and rocks (Ref. 22). Sulfur may offer an alternative to Portland cement as a binder in making concrete for use in iunar construction. Suifur concrete offers the following advantages that are relevance to lunar construction (Ref. 21):

- Compressive, tensile, and flexural strength as well as fatigue life are greater than those obtained with conventional Portland cement concrete.

- Rapid setting, achieving a minimum of $70-80 \%$ of ultimate compressive strength within 24 hours of casting.

- Higher chemical resistance against acids and salts.

- Low water permeability.

\section{E. Areas of Concern about Using Sulfur Concrete}

Temperature variations, which is a critical factor affecting the strength of sulfur concrete as it should not exceed $119^{\circ} \mathrm{C}$ (melting point of sulfur) as well as it should be below $96^{\circ} \mathrm{C}$ to prevent not only surface melting but volume change of sulfur. Another critical concern is the effect of low pressure and very low temperature on the sublimation of sulfur. The performance of sulfur in extreme conditions such as very low temperature and very low pressure is not known and must be investigated if sulfur concrete to be used as a construction material in space. The relatively poor durability of sulfur concrete in response to repeated thermal cycles imposes restrictions on base site selection. Lunar Polar Regions can be considered as options for preliminary base construction. The fact that Moon's poles are inclined 1.5 degrees from a perpendicular to ecliptic plane, the sun will always appear close to the horizon near poles as the Moon slowly rotates on its axis every 27.322 days (Fig. 9) (Ref. 23). Thus, topographically high and low points in vicinity of poles are potentially permanently illuminated or shadowed respectively. Another inviting aspect of polar sites is the potential with respect to astronomy. It is possible to view celestial objects for as long as desired if cryogenic telescopes are located in continuous darkness of polar regions.

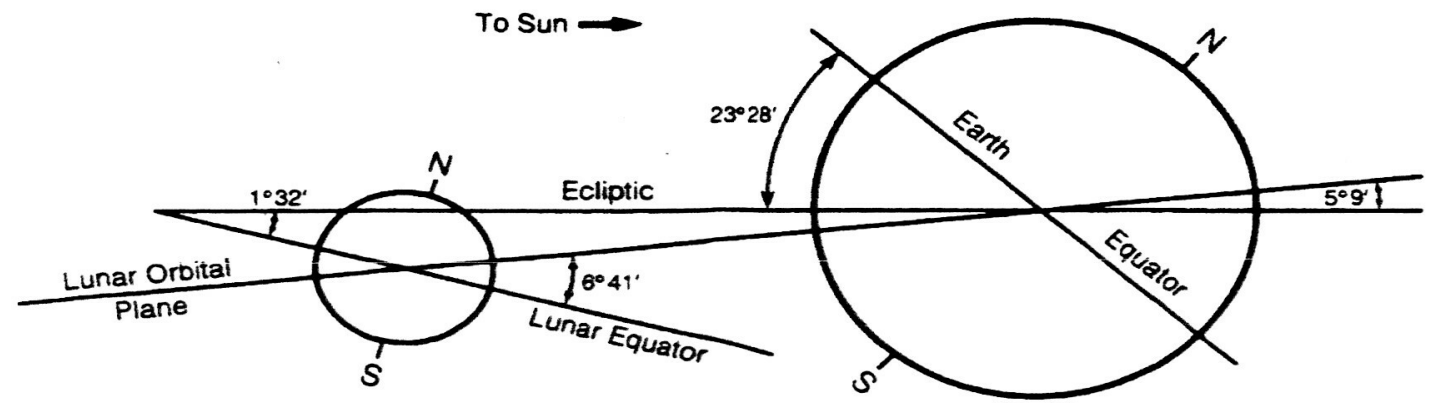

Fig. 9. Geometric Relationship between the Planes of Revolution and Rotation in the Earth-Moon System (Ref. 23)

8

American Institute of Aeronautics and Astronautics 


\section{F. Current Work}

It was found that both the compressive and tensile strengths of sulfur concrete are very promising and compare well with regular hydraulic cement concrete (Ref. 24). The optimal strength can be achieved for proportions of $35 \%$ sulfur and $65 \%$ aggregate by mass. To further simulate the extreme temperature conditions prevalent on the surface of the Moon, the effect of the freeze and thaw and constant extreme cold temperature on the strength of sulfur concrete are being investigated at the University of Alabama in Huntsville. In addition, the result of the addition of dicyclopentadiene on the freeze/thaw and the constant extreme cold environments of sulfur concrete is also being looked into. Dicyclopentadiene is a polymer additive that prevents internal strain during thermal variation.

The freeze and thaw experiments consist of subjecting the specimens to a large number of freeze/thaw cycles. Each cycle consists of 12 hours of freeze and 12 hours of thaw. Another experiment consists of placing the sulfur specimens in a constant cold environment for at least four weeks. After exposure, the specimens are tested and results are compared to the virgin samples. Preliminary results are presented in another paper at this conference (Ref. 26).

Currently research is underway to investigate the effect of silica (glass fiber) on the strength and durability performance of sulfur concrete. Silica can be used as a reinforcing element for sulfur. Mechanical and durability performances should provide some answers to the feasibility of using sulfur in space. The data gathered on sulfur concrete's durability in extreme temperature conditions should help us to select the proper sulfur concrete mix and to decide the proper location for a lunar base made from sulfur concrete.

\section{Glass Reinforcement Development}

Fiberglass and glass rods are ideal candidates for use in lunar construction. Fiberglass can be used in a number of applications including weaving cylindrical pressure vessels, electrical insulation, braided cables and reinforcement in structural materials. Glass rods can be utilized as struts, compression members in tensegrity elements and structural reinforcement. Both are prime candidate in-situ materials for use as reinforcement in lunar concrete structures.

Glass fiber reinforced polymer rebars are currently used in a large number of terrestrial applications where steel rebar will degrade or near strong electromagnetic fields. It is also much less thermally conductive than steel minimizing thermal expansion problems. In fact, it can be stronger than normal steel rebar. Glass rebar rods could also be made for pumped or cast concrete for in-situ applications.

Utilization of the lunar regolith for production of fiberglass and glass rods will require a knowledge of the glass forming capability of this material. Some work has been performed with lunar simulants. Tucker et. al.(Ref. 26) studied the fiber forming characteristics of Minnesota Lunar Simulant-1 (MLS-1) and Minnesota Lunar Simulant-2 (MLS-2). MLS-1 simulated the mare composition and MLS-2 the lunar highlands. It was found that MLS-2 was easier to draw into a fiber. However, both simulants led to "fragile" glasses which tended to crystallize quite readily. Addition of boric oxide ( $8 \mathrm{wt} . \%$ ) extended the viscosity such that continuous fibers were easily drawn using a fiber pulling apparatus. Glass formation appears to be easier with JSC-1 simulant. Bulk samples such as buttons can be cast as glass, as shown in Figure 10. 


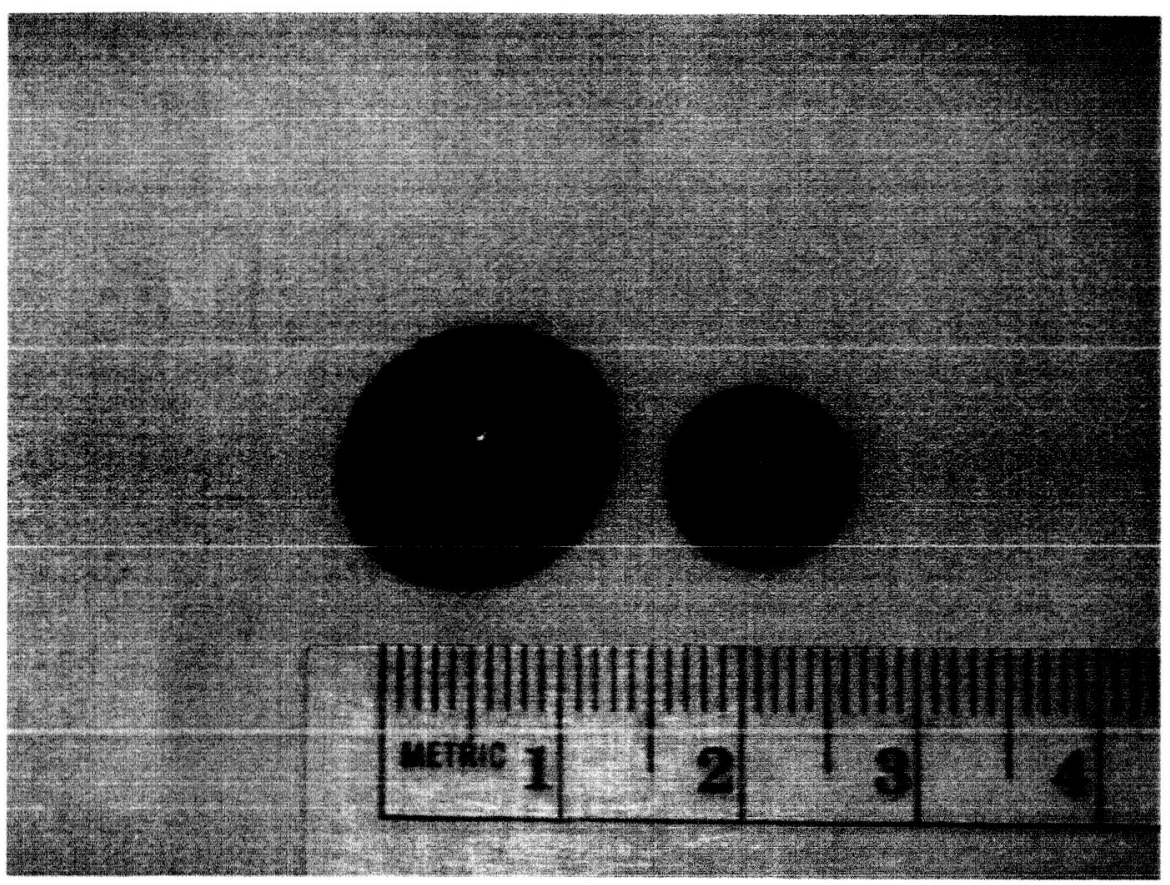

Figure 10. Bulk glass samples cast from JSC-1 lunar regolith simulant

We are in the process of characterizing the glass forming properties of JSC-1 lunar simulant to be used to study fiber formation and glass rod casting. Table 2 below shows the composition of JSC-1 compared with representative actual lunar soil (Ref. 27).

Table 2. Compositional differences between JSC-1 lunar regolith simulant and actual lunar soil

\begin{tabular}{|c|c|c|}
\hline Oxide & $\begin{array}{c}\text { JSC-1 Mean of Three } \\
\text { Concentration (wt \%) }\end{array}$ & $\begin{array}{c}\text { Lunar Soii (sampie 14163) } \\
\text { Concentration (wt \%) }\end{array}$ \\
\hline $\mathrm{SiO}_{2}$ & 47.1 & 47.3 \\
\hline $\mathrm{TiO}_{2}$ & 1.59 & 1.6 \\
\hline $\mathrm{Al}_{2} \mathrm{O}_{3}$ & 15.02 & 0 \\
\hline $\mathrm{Fe}_{2} \mathrm{O}_{3}$ & 3.44 & 17.8 \\
\hline $\mathrm{FeO}$ & 7.35 & 9.5 \\
\hline $\mathrm{MgO}$ & 9.01 & 11.4 \\
\hline $\mathrm{CaO}$ & 10.42 & 0.7 \\
\hline $\mathrm{Na}$ & 2.7 & 0.6 \\
\hline $\mathrm{K}_{2} \mathrm{O}$ & 0.82 & 0.1 \\
\hline $\mathrm{MnO}_{\mathrm{Cr}} \mathrm{O}_{3}$ & 0.18 & 0.2 \\
\hline $\mathrm{P}_{2} \mathrm{O}_{5}$ & 0.04 & 0 \\
\hline Total & 0.66 & 0 \\
\hline
\end{tabular}

DTA analysis of JSC-1 (Ref. 29) confirms that this material should be a good glass former. The parameter ( $T_{x^{-}}$ $T_{g}$ ) which is defined as the temperature difference between the crystallization temperature $\left(T_{x}\right)$ and the glass transition temperature $\left(\mathrm{T}_{\mathrm{g}}\right)$ is $126^{\circ} \mathrm{C}$. This parameter is used to describe the thermal stability of the glass during reheating. If fiber drawing is done by reheating the glass, it is critical that this difference be large. However, if the drawing is done at a temperature close to $T_{x}$, crystallization will occur during fiber drawing. Fiber drawing is normally done in the viscosity range of $10^{3}$ to $10^{6}$ poise. Thus it will be important to obtain viscosity versus temperature data. If reheating the glass is not viable, then drawing fibers above the liquidus will be attempted.

It is planned to produce glass fiber from JSC-1 which can be crimped during drawing producing fiber "rebar". The crimping will occur just as the fiber has left the jet zone before the fiber viscosity is too high for forming. JSC- 
1 will also be melted and poured into carbon molds to form small glass rods. These rods will then be annealed near $T_{\mathrm{g}}$ to alleviate thermal stresses. Glass-ceramic or ceramic rods can be produced by reheating the glass to the nucleation temperature to nucleate crystals, then heating to the growth temperature to grow the crystals. It is imperative to have knowledge of the nucleation (I) and growth (U) rates of the glass. Thus a study is being undertaken to determine these rates utilizing a technique developed by Chandra et. al. (Ref. 30) which utilizes differential thermal analysis to determine I and $U$.

\section{Test Status}

Prototype CC hardware built by the University of Southern California (USC) is currently being operated in the Prototype Development Laboratory (PDL) at NASAMSFC. In conjunction with the hardware, USC provided MSFC with the types of concrete, mixing ratios, and motion control files used during their research studies. Initial modifications to this hardware include the addition of limit switches, "stop" or "home" positions, addition of a $3^{\text {rd }}$ axis of motion to allow creation of more complex geometric shapes, software upgrades, and demonstration of the system using a batch of lunar regolith simulant-based concrete in place of Portland cement-based concrete. In the long term, this hardware will also be used to evaluate designs for automated starting, stopping and air purging of the system, continuous vs. batch processing, nozzle and trowel designs and materials, and incorporation of various reinforcement designs and materials.

\section{Summary}

Lunar Contour Crafting appears to be a viable methodology for construction of Lunar and Martian habitats. Construction technologies such as this hold much promise for development of systems requiring automated deployment. Development of such habitats pose tremendous challenges that can be met by the combination of innovative design with cutting-edge technologies that are appropriate for planetary surface habitats with multiple applications for Earth and beyond.

\section{Acknowledgments}

USC research on Contour Crafting has been supported by the National Science Foundation (NSF) under Grants No. 9522982, 9615690, and 0230398, and by a grant from the Office of Naval Research. This work was also performed partly at the Jet Propulsion Laboratory, California Institute of Technology, under a contract with the National Aeronautics and Space Administration (NASA). Portions of this work were also performed in support of the Marshall Space Flight Center under the Jacobs/Sverdrup Engineering, Science, and Technical Support (ES\&TS) Contract (No. NAS8-00187).

\section{References}

1. Khoshnevis, B. "Automated Construction by Contour Crafting - Related Robotics and Information Technologies," Journal of Automation in Construction - Special Issue: The Best of ISARC 2002, Edited by W. C. Stone, Vol 13, Issue 1, January 2004, pp 5-19.

2. Khoshnevis, B. and G. Bekey, "Automated Construction using Contour Crafting - Applications on Earth and Beyond," Journal of Rapid Prototyping, Vol. 9, No 2, pp 1-8, 2003 (Winner of Best Paper Award at ISARC 2002).

3. Kwon, H., S. Bukkapatnam, B. Khoshnevis, J. Saito, "Effect of Orifice Shape in Contour Crafting of Ceramic Materials", Journal of Rapid Prototyping, Vol. 8, No. 3, pp. 147-160, 2002.

4. Khoshnevis, B, S. Bukkapatnam, H. Kwan, and J. Sato, "Experimental Investigation of Contour Crafting using Ceramic Materials," Journal of Rapid Prototyping, Vol. 7, No. 1, 2001, pp.32-41.

5. Khoshnevis, B., R. Russell, H. Kwon, S. Bukkapatnam, "Crafting Large Prototypes," Refereed feature article in IEEE Robotics and Automation Magazine, pp 33-42, Sep. 2001. 
6. Backes, P.G., John Beahan and Bruce Bon, "Interactive Command Building and Sequencing for Supervised Autonomy." In Proceedings IEEE International Conference on Robotics and Automation, pages 795-801, Atlanta, Georgia, May 1993.

7. Das, H., Tim Ohm, Curtis Boswell, Guillermo Rodriguez, Eric Paljug, Robert Steele, Ed Barlow, "Telerobotics for Microsurgery", Proceedings of the 1996 IEEE Engineering in Medicine and Biology 18th Annual International Conference, October-November, Amsterdam, The Netherlands,1996.

8. Flashner H.and M. Golat, " A New Methodology for Analysis of Nonlinear Periodic Systems", Journal of Nonlinear Dynamics, Vol. 28, pp. 29-51, (2002)

9. T. Huntsberger, A. Trebi-Ollenne, H. Aghazarian, P. Schenker, P. Pirjanian, H. Das Nayar, "Distributed Control of Multi-Robot Systems Engaged in Tightly Coupled Tasks," Autonomous Robots, vol. 17, no. 79-92, 2004.

10. Kim, W.S., A. I. Ansar, R. D. Steele, "Rover Mast Calibration, Exact Camera Pointing, and Camera Handoff for Visual Target Tracking," submitted to ICRA'05, 2004.

11. Kim, W.S., "Computer Vision Assisted Virtual Reality Calibration," IEEE Trans. on Robotics and Automation, pp. 450-464, June 1999.

12. Kim, W.S., "Virtual Reality Calibration and Preview/Predictive Displays for Telerobotics," Presence, MIT Press, vol. 5, no. 2, pp. 173-190, 1996.

13. Kim, W.S., B. Hannaford, and A. K. Bejczy, "Force-Reflection and Shared Compliant Control in Operating Telemanipulators with Time Delay," IEEE Trans. on Robotics and Automation, vol. 8, no. 2, pp. 176-185, Apr. 1992.

14. Schenker, P.S., T.L. Huntsberger, P. Pirjanian, A. Trebi-Ollennu, H. Das, S. Joshi, H. Aghazarian, A.J. Ganino, B.A. Kennedy, and M.S. Garrett, "Robot work crews for planetary outposts: Close cooperation and coordination of multiple robots," in Proc. SPIE Symposium on Sensor Fusion and Decentralized Control in Robotic Systems III, Vol. 4196, Boston, MA, Nov. 5-8, pp. 210-220, 2000.

15. Matsumoto, S., Yoshida, T., Kanamori, H., Takagi, K., "Construction Engineering Approach for Lunar Base Development", Journal of Aerospace Engineering Oct. 1998, pp. 129-137.

16. Horiguchi, T., Saeki, N., Yoneda, T., Hoshi, T., Lin, T.D., "Study on Lunar Cement Production using Hokkaido anorthite and Hokkaido Space Development Activities", Proceedings: $5^{\text {th }}$ International Conf. on Space, 1996.

17. Neville, A.M., Brooks, J.J., Concrete Technology, Longman Science \& Technical, NY, NY, 1987.

18. Bury, M., Jalbert, L., Mustaikis, S., "Taking Concrete to the Outer Limits," Concrete Construction, V. 40, No. 10,1995 , pp. $855-859$.

19. Lin, T.D., Skaar, S.B., O'Gallagher, J.J., "Proposed Remote-Control, Solar-Powered Concrete Production Experiment on the Moon", Journal of Aerospace Engineering, April 1997, pp. 104-109.

20. Lin, T.D., Tseng, L., Chou, S; "Lunar Concrete Made with The Dry-Mix/Steam-Injection Method", Proceedings of the $5^{\text {th }}$ International Conference on Space ' 96.

21. Gracia V. and Casanova, I, "Sulfur Concrete; A Viable Alternative for Lunar Construction," Proceedings: $6^{\text {th }}$ Conf. on Space '98, ASCE, pp, 585-591.

22. Leonard, R.S. and Johnson, S.W. (1988) "Sulfur-based Construction Materials for Lunar Construction." Proc. 1st International Conference. Space '88, ASCE, pp 1295-1307.

23. Heiken, G.H., Vaniman, D., and French, B.M., Eds., Lunar Sourcebook, Cambridge University Press, 1991, pp. 57-58. 
24. Omar, H.A., Issa, M.A., "Production of Lunar concrete Using Molten Sulfur," Proceedings: $4^{\text {th }}$ Conf. on Space" 94, ASCE, pp. 952-959.

25. Toutanji, H, "Strength and Durability Performance of Waterless Lunar Concrete", Proceedings: 43 ${ }^{\text {rd }}$ AIAA Aerospace Sciences Meetings, Reno, NV, January, 2004.

26. D.S. Tucker and E.C. Ethridge, "Processing Glass Fiber from Moon/Mars Resources" Space 98, 1998.

27. D.S. McKay, J.L. Carter, W.W. Boles, C.C. Allen, and J.H. Allton, "JSC-1: A New Lunar Soil Simulant", Engineering, Construction and Operations in Space IV, pp. 857-866, 1994.

28. J.J. Papike, S.B. Simon and J.C. Laul, "The Lunar Regolith: Chemistry, Mineralogy and Petrology", Rev. Geophys. Space Phys. 20, pp. 761-826, (1982).

29. Peтsoñal Communication from Chandra S. Ray, 2004.

30.C.S. Ray, X. Fang and D.E. Day, "A New Method for Determining the Nucleation and Crystal Growth Rate in Glasses", J. Amer. Ceram. Soc., 83, 4, pp. 865-872, 2000. 